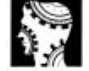

original papers to liaison services elsewhere, it may also belie a lack of recognition of psychosomatic disorders.

Liaison psychiatry demands a different set of specialised skills to those required in general adult psychiatry. The liaison psychiatrist must be adept at assessing relevant physical findings in addition to mental state, at engaging individuals with somatic presentations of psychiatric illness and at managing those with psychiatric and physical comorbidity. Such skills may not readily be learned outside of centres which have a welldeveloped specialist liaison service under consultant supervision. Nevertheless, a general adult team can do much to aid a positive attitude in the medical setting towards psychiatry, promote a bio-psychosocial approach to diagnosis, and increase the potential of physicians to treat common psychiatric disorders. Priority should be placed on fostering communication with non-psychiatric colleagues so as to optimise mutual learning.

\section{Acknowledgements}

Thanks to all members of the liaison team at Louth County Hospital.

\section{Declaration of interest}

None.

\section{References}

BABOR, T., CAETANO, R., CASSWELL, S., et al (2003) Alcohol: No Ordinary Commodity. Research and Public Policy. World Health Organization \& Oxford University Press.

COMHAIRLE NA NOSPIDÉAL (2004) Consultant Staffing in the Mental

Health Services, pp. 53-54.

Government Publications.

CRAWFORD, M. J. \& WESSELY, S. (1998) Does initial management affect rate of repetition of deliberate self-harm? BM 317, 985-990.

DEPARTMENT OF HEALTH AND CHILDREN: EXPERT GROUP ON MENTAL HEALTH POLICY (2006) A Vision for Change, pp. 154-157. Government Publications.

FREYNE, A., BUCKLEY, P., LARKIN, C., et al (1992) Consultation liaison psychiatry within the general hospital: referra pattern and management. Irish Medica Journal, 85, 112-114.

GILMAN, S. E. \& ABRAHAM, H. D. (2001) A longitudinal study of the orde of onset of alcohol dependence and major depression. Drug and Alcohol Dependence, 63, 277-286.

MOLYNEUX, G CRYAN E \& ELISA, D. (2006) The point-prevalence of alcohol use disorders and binge drinking in an Irish general hospital. Irish Journal of Psychological Medicine, 23, 17-20.

MOYER, A., FINNEY, J., SWEARINGEN $C$. et al (2002) Brief interventions for alcohol problems: a meta-analytical review of controlled investigations in treatment seeking and non-treatment seeking populations. Addiction, 97, 279-293.

NATIONAL CRIME COUNCIL (2003) Public Order Offences in Ireland. The Stationery Office Dublin.

O'KEANE, V.,WALSH, D. \& BARRY, S. 2005) Stark Facts. Irish Psychiatric Association.

ROYAL COLLEGE OF PSYCHIATRISTS (2003) The Psychological Care of

Medical Patients: A Practical Guide (CR108). Royal College of Psychiatrists ROYAL COLLEGE OF PSYCHIATRISTS (2004) Assessment Following Selfharm in Adults (CR 122). Royal College of Psychiatrists.

SWANICK, G. \& CLARE, A. (1994) Inpatient liaison psychiatry: the experience of two Irish genera hospitals without psychiatric units. Irish Journal of Psychological Medicine, 11 $123-125$

Claire Flahavan Registrar, Mater/UCD Rotational Training Scheme in Psychiatry, St James' Child Guidance Clinic, 1 James Street, Dublin 8, Ireland, email:cflahavan@ gmail.com

\title{
Nurse-led liaison psychiatry service for older adults: service evaluation
}

\section{AIMS AND METHOD}

To comprehensively describe a nurseled consultation liaison service for older adults by retrospectively reviewing all referrals received in 2006 and comparing them against other services and benchmark reports.

RESULTS

Of the 298 individuals referred to psychiatric services from other

\author{
hospital wards, 120 were aged $85-94$ \\ years old $(40 \%), 193$ were male $(65 \%)$ \\ and 152 were referred from geriatrics \\ (51\%). A majority of 204 have not had \\ previous contact with psychiatric \\ services (69\%). The most common \\ diagnosis was dementia (33\%, \\ $n=88$ ), with $27 \%$ individuals ( $n=65$ ) \\ being referred onwards to secondary \\ care.
}

The publication of Who Cares Wins by the Royal College of Psychiatrists (2005) has provided the best available benchmark for the service structure of liaison psychiatry for older adults. The development of specific liaison services is now a priority. Nurse-led consultation for older adult liaison services is gaining popularity. The biggest contribution of liaison nursing teams lies in planning effective discharge, continuity of care and education
(Mukaetova-Ladinska, 2006). A randomised controlled trial showed it can be effectively implemented (Baldwin et al, 2004). The efficacy is equivalent to doctor-led consultation models which may have cost-saving implications (Baldwin et al, 2004).

Who Cares Wins states that the multidisciplinary approach has advantages over the consultation method in terms of a more specialist assessment, shortened 
length of stay, decreased mortality, more mental health reviews and increased compliance with the management plan (Royal College of Psychiatrists, 2005), which has been confirmed through other surveys (Whelan et al, 2007). Despite this, $73 \%$ of mental health services in the UK use the traditional sector-based consultation model (Bentley et al, 2003). This evaluation comprehensively reviews, over a 1-year period, all liaison referrals to old age psychiatry services. We are unaware of any studies which comprehensively describe a nurse-led old age liaison service detailing patient demographics and outcomes over a year.

\section{Method}

\section{Setting and service}

The study was carried out at Wrexham Maelor Hospital, part of the North East Wales National Health Service (NHS) Trust which serves approximately 330000 people. The liaison service, using a consultation nurse model, has been operating there since 2000 . The team was composed of a registered mental nurse band 6 , working full time, who assessed all referrals, including those from accident and emergency, with additional input from a healthcare support worker. The nurse also received 1hour weekly supervision from a consultant old age psychiatrist. If required, brief community support by the support worker was possible upon discharge. Referrals were made on standardised forms which included two non-mandatory instruments - the 6-item Cognitive Impairment Test (Brooke \& Bullock, 1999) and the 4-item Geriatric Depression Scale (Shah et al, 1999). For individuals presenting with acute confusion, it was expected that the local acute hospital trust protocol for managing delirium had been first tried.

The individuals referred, already open to the community psychiatric team, were not assessed by the liaison service because of the limited capacity of the nurse and to improve continuity of care. Such individuals were seen by their own community psychiatric nurse and were excluded from this study. The previous service used the traditional doctor-led sector-based model, with referrals being assessed by the relevant staff grade doctor or consultant, with limited opportunity for followup or staff and family education because of time constraints. Since the introduction of the liaison service, it is the team's impression that referral rates have not increased, but detection rates have improved for dementia owing to their ability to spend longer assessing each individual. Staff and family satisfaction through improved communication and education have also improved. Patients and carers particularly appreciated the opportunity for brief community follow-up, with fewer requiring a community mental health team referral.

\section{Evaluation}

Each standardised referral form was scrutinised for the person's demographics, their type of accommodation, the specialty of the referrer, the reason for admission and the referrer's statement of the presenting problem. The length of stay in hospital prior to referral was also recorded, as was whether assessment tools were used and which psychotropic medications were prescribed on referral. The psychiatric diagnosis, the outcome for assessed individuals, the subsequent discharge accommodation and, if an assessment did not actually occur, why that was so, was obtained from the liaison assessment.

Diagnoses were established using the ICD-10 criteria (World Health Organization, 1992). The data were analysed using Simple Interactive Statistical Analysis (Uitenbroek, 1997); chi-squared tests were used to investigate the significant characteristics of particular groups, with the $P$-value for statistical significance set at 0.05 . Odds ratios were calculated to measure effect size. The team chose groups of individuals for analysis and comparison based on whether it could make an important contribution, namely those with no previous or current psychiatric history, those referred into secondary care and those discharged into care.

\section{Results}

Wrexham Maelor Hospital has a 659-bed capacity. It received 24812 acute admissions in 2006, of which 4906 were for surgery, 4663 for medicine, 2414 for orthopaedics and 2365 for geriatrics. The study identified 298 referrals (the total number for 2006) to psychiatry from the four units, all for people aged over 65 years. Seven of them died prior to being assessed and 13 more died prior to discharge; the mean length of stay prior to referral was 13.7 days. Most referrals were made by nursing staff rather than medical staff. In only $36 \%$ of referrals $(n=107)$ had screening instruments been used. A third $(69 \%, n=204)$ had no previous or current contact with psychiatric services; $95 \%$ of those referred and accepted ( $n=283$ ) were seen within the 3-day policy limit. Basic demographics including gender, age, accommodation type and referral source are described in Table 1 (the reason for admission, the referring problem, previous contact with psychiatric services and psychotropic medications listed on referral are also described).

The outcomes for assessed individuals, including reasons for non-assessment, psychiatric diagnosis, onward referrals and discharge placement, are presented in Table 2. The team's interventions included a one-off assessment in $62 \%$ individuals $(n=184)$, with the rest requiring further reviews by the liaison nurse because of the complexity of presentation and risk. All those who received brief community liaison follow-up by the support worker $(13 \%, n=33)$ also received weekly support during their in-patient stay, as decided by the team according to who needed further emotional support, including carers. The support worker also tended to use community support for those entering into a care home to provide a link between in-patient stay and primary care during the transition period.

For those who saw a staff grade or a consultant psychiatrist during their in-patient admission, this was 
田

original papers

\section{Table 1. Basic demographics and referral information}

\begin{tabular}{lc} 
Characteristic & $n(\%)$ \\
\hline Gender & \\
Men & $193(65)$ \\
Age, years & \\
$65-74$ & $63(21)$ \\
$75-84$ & $105(35)$ \\
$85-94$ & $120(40)$ \\
>95 & $10(4)$ \\
Accommodation & \\
Independent & $246(83)$ \\
Residential & $29(10)$ \\
Nursing & $13(4)$ \\
Sheltered & $10(3)$ \\
Referral source & \\
Geriatrics & $152(51)$ \\
Medicine & $89(30)$ \\
Orthopaedics & $38(13)$ \\
Surgery & $17(6)$ \\
Reason for admission & \\
Emergency & $102(34)$ \\
Confusion & $48(16)$ \\
Fall & $45(15)$ \\
Fracture & $31(10)$ \\
Other & $25(9)$ \\
Chronic illness relapse & $21(7)$ \\
Elective procedure & $14(5)$ \\
Self-harm & $12(4)$ \\
Referring problem & \\
Confusion & $169(57)$ \\
Mood problem & $70(24)$ \\
Self-harm & $10(3)$ \\
Capacity assessment & $13(4)$ \\
Anxiety & $15(5)$ \\
Other & $15(5)$ \\
Placement & $6(2)$ \\
Psychotropic medications on referral & \\
Total on medication & $154(52)$ \\
Antipsychotic & $81(27)$ \\
Benzodiazepine & $39(13)$ \\
Antidepressant & $26(9)$ \\
Cholinesterase inhibitor & $4(1)$ \\
Other & $4(1)$ \\
&
\end{tabular}

Table 2. Outcomes for assessed patients

\begin{tabular}{lc} 
Outcome & $n(\%)$ \\
\hline Reason for non-assessment & \\
Open to secondary care & $48(47)$ \\
Medically inappropriate & $31(30)$ \\
Discharged before seen & $16(16)$ \\
Died prior to assessment & $7(7)$ \\
Total not assessed & $102(34)$ \\
Psychiatric diagnosis (ICD-10) & \\
Dementia & $88(33)$ \\
Delirium & $52(20)$ \\
Mood & $50(19)$ \\
None & $27(10)$ \\
Alcohol dependence & $19(8)$ \\
Neurosis & $12(4)$ \\
Psychosis & $7(3)$ \\
Other & $6(2)$ \\
Personality & $3(1)$ \\
Outcomes for assessed patients & \\
Liaison only as an in-patient & $115(47)$ \\
Secondary care referral & $65(27)$ \\
Brief community liaison follow-up & $33(13)$ \\
Psychiatrist consultation & $20(8)$ \\
In-patient admission & $7(3)$ \\
Alcohol services & $5(2)$ \\
Discharge placement & \\
Home & $114(60)$ \\
Placement & $38(20)$ \\
Community NHS hospital & $26(13)$ \\
&
\end{tabular}

mainly attributed to diagnostic difficulty, psychotropic medication review, review before admission to the psychiatry ward, challenging capacity assessments, and where the nurse was experiencing undue difficulty in the staff dynamic between psychiatry and the general hospital. At discharge from the team, $27 \%$ of individuals $(n=65)$ were referred to secondary care, namely older person's mental health services such as a community mental health team, memory clinic, out-patient clinic and day hospital. (The significance of differences between selected variables is presented in Table 3.)

Table 3. Characteristics of the variables analysed

\begin{tabular}{|c|c|c|c|}
\hline Characteristic & $\chi^{2}$ & $P$ & Odds ratio $(\mathrm{Cl})$ \\
\hline \multicolumn{4}{|l|}{ No previous or current psychiatric history } \\
\hline Received liaison follow-up & 22.89 & $<0.01$ & $3.62(2.14-6.13)$ \\
\hline Diagnosed with delirium & 5.14 & 0.02 & $2.52(1.17-5.42)$ \\
\hline Prescribed psychotropic medications on referral & 7.80 & $<0.01$ & $0.48(0.29-0.79)$ \\
\hline \multicolumn{4}{|l|}{ Referred to secondary care } \\
\hline Diagnosed with dementia & 36.74 & $<0.01$ & $5.89(3.26-10.65)$ \\
\hline Admitted from own home & 5.01 & 0.03 & $4.07(1.21-13.62)$ \\
\hline Received liaison follow-up & 12.03 & $<0.01$ & $0.34(0.19-0.62)$ \\
\hline \multicolumn{4}{|l|}{ Discharged into care } \\
\hline Received liaison follow-up & 34.78 & $<0.01$ & $10.49(4.31-25.50)$ \\
\hline Admitted with a fracture & 4.47 & 0.03 & $2.62(1.15-5.98)$ \\
\hline Diagnosed with delirium & 8.10 & $<0.01$ & $2.54(1.37-4.72)$ \\
\hline Admitted with falls & 4.50 & 0.03 & $2.29(1.13-4.67)$ \\
\hline Diagnosed with dementia & 3.48 & 0.06 & $2.08(1.03-4.21)$ \\
\hline Admitted from own home & 7.79 & $<0.01$ & $0.34(0.16-0.70)$ \\
\hline Male & 9.59 & $<0.01$ & $0.28(0.13-0.63)$ \\
\hline
\end{tabular}




\section{Discussion}

The service received a large number of referrals for its size, comparable to King's College Hospital, London (336 patients in 2001; Hanlon et al, 2004); this has not changed over the past 5 years. Referrals were more frequent during winter, confirming previous research (Benbow et al, 1998), and may have implications for staffing. The majority of individuals lived independently prior to admission, challenging the stereotyped view of the incapacitated elderly person. There was a reluctance to use the non-mandatory assessment tools before referral and these tended to be used on people with behavioural disturbance or non-adherence.

Most individuals were referred from geriatrics, with little referrals from surgery and orthopaedics, in line with previous studies (Bentley et al, 2003). There are noticeable differences in the number of referrals of people aged over 65 years old in medicine (34\%), surgery (42\%), and elective (72\%) and trauma (21\%) orthopaedics, and also in numbers of admission per year per specialty with the referral rate per specialty. It is estimated that for one old age psychiatry referral, 16 admissions are made to geriatrics, 18 to medicine, 38 to orthopaedics and 121 to surgery (Boddy et al, 1977; Burley et al, 1979;

Asimakopoulous et al, 1998; Gomberg et al, 1999).

'Acute emergency', confusion, falls and fractures constituted the most common reasons for acute admission. With $69 \%$ of those referred having no previous contact with psychiatric services, many elderly individuals present via such acute events. Liaison services have an important role in detecting mental illness and signposting thereafter, which compares well with published data (Ashaye et al, 2006). The most common referring problem was confusion. Other problems included a mood disorder, self-harm, capacity assessment, anxiety and assessment of placement, and compares similarly with other surveys (Rao, 2001; Ashaye et al, 2006). The rate of self-harm (4\%) was comparable with that in other services (Gash et al, 2005). Over half of those referred were already prescribed psychotropic medications which tended to be antidepressants. With only five referrals asking for a psychotropic medication review, medication management should become an area for potential service development.

This survey re-affirms the three D's of old age psychiatry - dementia, delirium and depression - and is comparable with Who Cares Wins, with prevalence of $31 \%, 20 \%$ and $29 \%$ respectively, and other surveys such as Whelan et al's (2007) with prevalence of $37 \%, 26 \%$ and $24 \%$ respectively. For rarer diagnoses (anxiety, psychosis and alcohol dependence) the prevalence was within the ranges in Who Cares Wins, except for alcohol dependence (it was diagnosed in $8 \%$ of individuals which may be caused by local patterns of use - Who Cares Wins and other surveys (Whelan et al, 2007) state a range of $1-5 \%$ ).

Of those referred to a community mental health team, day hospital, memory clinic or out-patient clinic, individuals tended to come from their own home, be diagnosed with dementia and be less likely to receive liaison support worker follow-up owing to their more complex needs requiring a community psychiatric nurse support. For those who returned home without a secondary care referral, brief community liaison support has been used frequently to bridge the gap between inpatient stay and primary care, and to provide postdelirium counselling. Individuals discharged into care were mostly those presenting with acute events such a fracture, fall and delirium. They received brief liaison follow-up only, considering the enhanced support in the care home environment.

The results of our survey are limited by the subjective nature of diagnosis, omitted information on the assessment forms and those patients with psychiatric morbidity not referred. Based on the data collected, the nurse-led consultation service model functions well in comparison with others which mainly use the traditional medically-led consultation model. The service uses a novel approach for post-discharge community support with a healthcare support worker. Being nurse-led, with targeted medical support as needed, the service may be cost-saving. It identifies many individuals with dementia that had no previous contact with psychiatry, and engages them into community services. As referrals from orthopaedics and surgery are improved, it is likely that even more people with dementia would be identified earlier.

\section{Declaration of interest}

None.

\section{Acknowledgements}

We thank the North East Wales NHS Trust and Dr M. Krishna for his statistical and editorial support.

\section{References}

ASHAYE, K., LAMBOURNE, A. \& LAMBOURNE, P. (2006) Liaison psychiatry and undetected dementia in hospitals. Progress in Neurology and Psychiatry, 10, 8-13.

ASIMAKOPOULOUS, G., HARRISON, R. \& MAGNUSSEN, P. A. (1998) Preadmission clinic in an orthopaedic department: evaluation over a 6month period. Journal of the Royal College of Surgeons of Edinburgh, 43, 178-181.

BALDWIN, R., GORING, H., MARRIOT, A., et al (2004) Does a nurse-ledmental health liaison service for older people reduce psychiatric morbidity in acute general medical wards? A randomised controlled trial. Age and Aging, 33, 472-478.

BENBOW, S. \& COLLINSON,Y. (1998) The role of an old age psychiatry consultation liaison nurse. International Journal of Geriatric Psychiatry, 13, 159-163.
BENTLEY, K., CAMERON, I. \& HOLMES J. (2003) A UK survey of psychiatric services for older people in general hospitals. International Journal of Geriatric Psychiatry, 18, 716-721.

BODDY, F. A., JENNETT, B. \& STRANG, I.W. (1977) Patients in acute surgical wards: a survey in Glasgow. BMJ, $\mathbf{1}$, 545-548.

BROOKE, P. \& BULLOCK, R. (1999) Validation of the 6 -item cognitive impairment test with a view to primary care usage. International Journal of Geriatric Psychiatry, 14, 936-940.

BURLEY, L. E., CURRIE, C. T., SMITH, R. G., et al (1979) Contribution from geriatric medicine within acute medical wards. BMJ, 2, 90-92.

GOMBERG, B. F. C., GRUEN, G. S., SMITH,W. R., et al (1999) Outcomes in acute orthopaedic trauma: a review of 130506 patients by age. Injury, 30, 431-437. original papers 
HANLON, C., MUJIC, F., PRINCE, M., et al RAO, R. (2001) 'Sadly confused': the 2004) Comparison of liaison psychiatry detection of depression and dementia service models for older patients. Psychiatric Bulletin, 28, 171-173.

original papers LAMPRECHT, H., PAKRASI, S., GASH, A., et al (2005) Deliberate self-harm in older people revisited. International Journal of Geriatric Psychiatry, 20 $1090-1096$

MUKAETOVA-LADINSKA, E. (2006) Towards living long and being healthy - the challenge for liaison psychiatric services for older adults. Age and Ageing, 35, 103-105. on medical wards. Psychiatric Bulletin $25,177-179$

ROYAL COLLEGE OF PSYCHIATRISTS (2005) Who Cares Wins. Improving the Outcome for Older PeopleAdmitted to the General Hospital. Royal College of Psychiatrists (http://www.rcpsych. ac.uk/PDF/WhoCaresWins.pdf)

SHAH, A., PHONGSATHORN, U., BIELAWSKA, C., et al (1999) Screening for depression among geriatric inpatients with short versions of the

Geriatric Depression Scale.

International Journal of Geriatric Psychiatry, 11, 915-918.

UITENBROEK, D. G. (1997) SISA

Binomial (http://

www.quantitativeskills.com/sisa/

distributions/binomial.htm).

OCALTHORGANIZATION (1992)

ICD-10 Classification of Mental and Behavioural Disorders. Clinical Description and Diagnostic Guidelines. WHO.

WHELAN, P., BURTON, S. \& LAWSON, K. (2007) Service innovation: an old age liaison psychiatry service. Psychiatric Bulletin, 31, 145-147.

*Daniel Anderson Specialty Registrar in Old Age Psychiatry, Knowsley Older Adults Community Mental HealthTeam, Willow House, 168 Dragon Lane, Whiston, Liverpool L3530Y, email: danielanderson@nhs.net, Howard Cattell Consultant in Old Age Psychiatry, Elaine Bentley Registered Mental Nurse in Old Age Liaison Psychiatry 